\title{
Sustainability of collaborative care management for depression in primary care settings with academic affiliations across New York State
}

Nathalie Moise ${ }^{1 *}$, Ravi N. Shah², Susan Essock², Amy Jones ${ }^{3}$, Jay Carruthers ${ }^{3}$, Margaret A. Handley ${ }^{4}$, Lauren Peccoralo ${ }^{5}$ and Lloyd Sederer ${ }^{6}$

\begin{abstract}
Background: In a large statewide initiative, New York State implemented collaborative care (CC) from 2012 to 2014 in 32 primary care settings where residents were trained and supported its sustainability through payment reforms implemented in 2015. Twenty-six clinics entered the sustainability phase and six opted out, providing an opportunity to examine factors predicting continued CC participation and fidelity.
\end{abstract}

Methods: We used descriptive statistics to assess implementation metrics in sustaining vs. opt-out clinics and trends in implementation fidelity 1 and 2 years into the sustainability phase among sustaining clinics. To characterize barriers and facilitators, we conducted 31 semi-structured interviews with psychiatrists, clinic administrators, primary care physicians, and depression care managers (24 at sustaining, 7 at opt-out clinics).

Results: At the end of the implementation phase, clinics opting to continue the program had significantly higher care manager full-time equivalents (FTEs) and achieved greater clinical improvement rates (46\% vs. $7.5 \%, p=0.004)$ than optout clinics. At 1 and 2 years into sustainability, the 26 sustaining clinics had steady rates of depression screening, staffing FTEs and treatment titration rates, significantly higher contacts/patient and improvement rates and fewer enrolled patients/FTE.

During the sustainability phase, opt-out sites reported lower patient caseloads/FTE, psychiatry and care manager FTEs, and physician/psychiatrist CC involvement compared to sustaining clinics. Key barriers to sustainability noted by respondents included time/resources/personnel (71\% of respondents from sustaining clinics vs. $86 \%$ from opt-out), patient engagement (67\% vs. $43 \%$ ), and staff/provider engagement (50\% vs. 43\%). Fewer respondents mentioned early implementation barriers such as leadership support, training, finance, and screening/referral logistics. Facilitators included engaging patients (e.g., warm handoffs) (79\% vs. $86 \%$ ) and staff/providers (71\% vs. 100\%), and hiring personnel (75\% vs. 57\%), particularly paraprofessionals for administrative tasks (67\% vs. 0\%).

Conclusions: Clinics that saw early clinical improvement and who invested in staffing FTEs were more likely to elect to enter the sustainability phase. Structural rules (e.g., payment reform) both encouraged participation in the sustainability phase and boosted long-term outcomes. While limited to settings with academic affiliations, these results demonstrate that patient and provider engagement and care manager resources are critical factors to ensuring sustainability.

Keywords: Depression, Sustainability, Primary health care

\footnotetext{
*Correspondence: nm2562@cumc.columbia.edu

Oral presentation at Academy Health Dissemination and Implementation

Conference in Washington, DC on December 15, 2016

${ }^{1}$ Center for Behavioral and Cardiovascular Health, Department of Medicine,

Columbia University Medical Center, 622 W. 168th Street, PH9- Room 321,

New York, NY 10032, USA

Full list of author information is available at the end of the article
}

(c) The Author(s). 2018 Open Access This article is distributed under the terms of the Creative Commons Attribution 4.0 International License (http://creativecommons.org/licenses/by/4.0/), which permits unrestricted use, distribution, and reproduction in any medium, provided you give appropriate credit to the original author(s) and the source, provide a link to the Creative Commons license, and indicate if changes were made. The Creative Commons Public Domain Dedication waiver (http://creativecommons.org/publicdomain/zero/1.0/) applies to the data made available in this article, unless otherwise stated. 


\section{Background}

More than 100 randomized clinical trials establish that collaborative care (CC) is an effective way manage depression in primary care settings [1-3]. In CC, depression care managers (DCMs), typically nurses or licensed social workers, provide regular, proactive monitoring, treatment-to-target (using standardized screening tools to track progress toward targeted goals through problem-solving therapy and/ or working with primary care providers to intensify antidepressants) and registry maintenance (i.e., tracking enrolled patients with depression). CC also includes regular systematic psychiatric caseload reviews and consultation for patients not improving [1,3-5]. CC has been shown to improve depression, quality of life, and productivity [6-9], while reducing mortality [10] and healthcare costs [11].

Despite randomized control trial findings, penetration of CC remains low. Recent efforts to implement CC in real-world settings, including safety net clinics, suggest multiple implementation barriers [12-15]. The DIAMOND trial, a state-wide Minnesota initiative that included implementation support, training, and monthly bundled payments, found wide variations in implementation strategies [16] but that poor physician and patient participation likely limited program effectiveness [17]. Prior studies identified additional implementation barriers, including lack of resources, space, implementation readiness, leadership support and knowledge, and most importantly, financial barriers such as lack of mental health care reimbursement for care managers and other non-physicians [3, 18-21]. Few prior studies focused on primary care settings where residents are trained; these settings may have unique barriers to implementation and sustainability given variability in provider comfort with and training in depression management [22-24].

In 2012, the New York State (NYS) Office of Mental Health $(\mathrm{OMH})$, in partnership with the NYS Department of Health (DOH), implemented a 2.5-year CC initiative in 32 primary clinics with academic affiliations (where $\geq$ 1 residents were trained) and where approximately 1 million patients received care. This was a Center for Medicare Services Hospital Medical Home Demonstration project and among the largest statewide initiatives to facilitate CC. To address prior barriers, the CC program provided flexible grant funding for staff and equipment, technical assistance, training, training/upkeep of registries (selected by clinics according to their infrastructure), monthly data submission for monitoring (e.g., clinic screening, enrollment, and remission rates), and quality-improvement activities, as previously described [25]. In 2014, 2 years after implementation, mean depression screening rate across the sites was $85 \%$ (vs. $63 \%$ in year 1), CC enrollment was $43 \%$ (vs. $35 \%$ ), and clinical improvement (defined as percentage of those enrolled at least 16 weeks with last Patient Health Questionnaire $[\mathrm{PHQ}]<10$ ) was $45 \%$ (vs. 16\%) [25].
After the grant period, $\mathrm{OMH}$ and $\mathrm{DOH}$ established Medicaid reimbursement rules designed to offer a sustainable financial structure in these 32 clinics and to incentivize high-quality CC implementation statewide. Starting in 2015, they implemented a $\$ 150$ per-member per-month supplemental payment for adult Medicaid patients receiving depression treatment using the $\mathrm{CC}$ model. Clinics received $75 \%$ of this fee for enrolling, tracking, and treatment at least once monthly and 25\% for achieving continued engagement with the patient and either clinical improvement after 3 months of treatment or documented intervention to address lack of improvement. DOH/OMH supplemented this shift to measurement-based reimbursement (also known as "value-based purchasing" with ongoing training and monitoring. As of 2018, there were over 150 participating clinics, both academic and nonacademic.

To date, there has been little focus on the effectiveness of CC sustainability efforts (e.g., measurement-based reimbursement strategies) or granular assessments of the challenges of transitioning from an implementation into sustainability period. Twenty-six of the original 32 clinics with academic affiliations in the CC demonstration projects opted to enter a sustainability period by enrolling in the Medicaid Reimbursement program (herein called sustaining clinics) and six opted out. This provided an opportunity to examine factors predicting continued CC participation and implementation fidelity. Using a mixed-methods approach, we sought to (1) examine whether clinics sustaining vs. opting out of CC differed in key early implementation fidelity metrics, (2) examine long-term CC fidelity among clinics opting to enroll in a sustainability initiation, and (3) describe barriers and facilitators to $\mathrm{CC}$ sustainability. Our aim was to inform future practice, policy, and financing of primary care behavioral interventions.

\section{Methods \\ Overview}

Overall, 32 clinics participated in the OMH implementation initiative from 2012 to 2014. In 2015, NYS launched the Medicaid reimbursement program, which included training and measurement-based reimbursement, to support the sustainability phase. Twenty-six of the original 32 clinics opted to enter the sustainability phase while six opted out (Fig. 1). Using descriptive statistics, we compared end of CC implementation metrics in 26 sustaining vs. 6 opt-out clinics. We then analyzed 1- and 2-year trends in CC metrics (newly derived for the sustainability phase) among sustaining clinics. To characterize barriers and facilitators in the sustainability phase, we used purposive sampling methods and conducted 31 semi-structured interviews with psychiatrists, clinic administrators, primary care physicians, and 


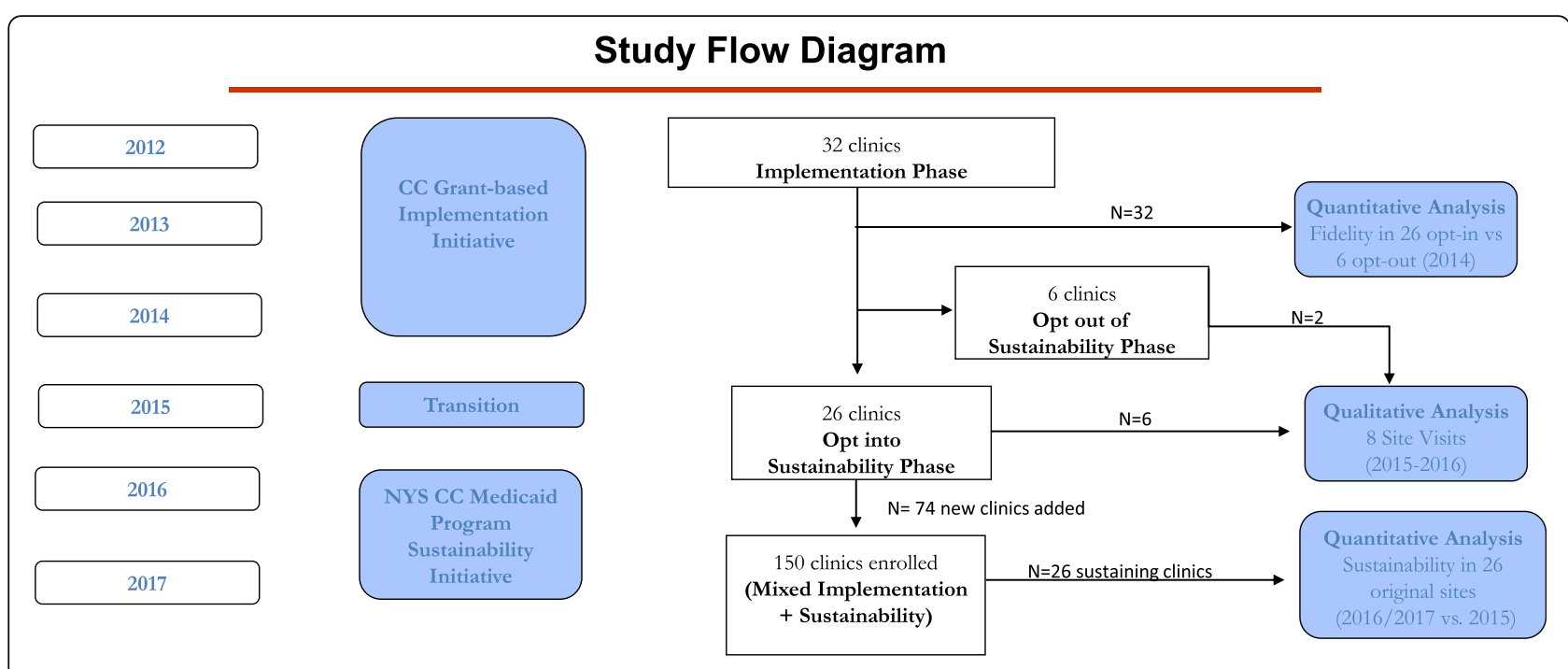

Fig. 1 Study flow diagram of the quantitative and qualitative assessments of the NYS Collaborative Care Medicaid Reimbursement Program

depression care managers (24 at six sustaining clinics, 7 at two opt-out clinics).

\section{Description of healthcare systems}

The 32 clinics represented 19 medical centers with academic affiliations (defined as hospital systems where $\geq 1$ residents are trained) caring for approximately one million patients. Overall, 11 healthcare systems (17 clinics) were part of New York City Health and Hospital $(\mathrm{H}+\mathrm{H})$, the largest public health care system in the USA, providing care across 70 locations, a low-cost health insurance plan, and population-based care, while 8 (15 clinics) were non- $\mathrm{H}+\mathrm{H}$ centers (academic health systems only). Clinic-reported populations ranged in size from 2000 patients/year to 30,000 patients/year.

\section{Phase 1: Quantitative analyses}

We previously published results of the NYS CC Initiative (2012-2014) [25]. Here, we compare sustaining $(n=26)$ and opt-out $(n=6)$ clinics using 2014 metrics: (1) percent and number of patients screened for depression using the Patient Health Questionnaire (PHQ)-2 and/or PHQ-9 in the calendar year; (2) DCM full-time equivalents (FTEs), a proxy for maintaining an integrated, dedicated care manager; (3) number of patients currently enrolled in CC program (including overlap from prior quarters) per DCM FTE; (4) number and percentage of patients screening positive for depressive symptoms enrolled in CC per calendar year; (5) $N$ and percentage of individuals enrolled in $\mathrm{CC}$ for 16 weeks or greater with PHQ-9 < 10; (6) number and percentage of enrolled individuals with a psychiatric consult; and (7) number and percentage enrolled 6 months still receiving medications or therapy.
We then focused on the sustainability phase metrics (2015-2017) provided quarterly by sustaining clinics $(n=26)$. Measures 1-3 were identical to the implementation period though there may have been reporting variability in "patients enrolled/FTE." OMH added or refined the remaining as follows: median PHQ-9 of those enrolled; percent of individuals enrolled in CC with $\geq 3$ DCM contacts; percent enrolled at least 70 days (10 weeks) with clinical improvement (PHQ-9 $<10$ and/or 50\% reduction in depressive symptoms); and percent of those in treatment for $\geq 70$ days who did not improve but (a) had their treatment changed and (b) received psychiatry consultation. Given the change in metrics, we focused analyses on the change in metrics at 1 and 2 years into sustainability compared to the earliest metrics in the sustainability phase (hereto referred to as baseline).

We used descriptive statistics (counts, medians, interquartile ranges), Mann-Whitney $U$ tests, and sign tests to (1) compare implementation metrics in sustaining and opt-out clinics and (2) assess the differences in metrics 1 and 2 years into the sustainability phase compared to baseline sustainability among sustaining clinics. To ensure similarities across analyses (e.g., some measures were year-to-date vs. by quarter), we used the most widely available quarter (quarter 3) for all analyses (including baseline).

\section{Phase 2: Qualitative analyses}

The OMH Chief Medical Officer invited the 32 original CC initiative clinics to participate in stakeholder interviews about the NYS CC program. Of the original 32 clinics, 30 agreed to participate in site visits (Fig. 1). Using a purposive sampling approach to include both sustaining and opt-out clinics, a psychiatrist (R.S.) and internist (N.M.) not otherwise involved in the CC initiative conducted site visits and interviews between December 2015 and May 2016 to assess barriers and 
facilitators to sustaining CC. We conducted site visits until we reached saturation (i.e., additional interviews ceased to identify additional themes) [26] in both sustaining and opt-out clinics. Interviewers asked that a PCP (preferably the implementation lead), administrator, DCM, and psychiatrist be available for interview. The New York State Psychiatric Institute institutional review board approved the project.

\section{Interview guide}

We developed the interview guide based on interviews with OMH clinical leadership and prior research on fidelity factors that correlate with CC implementation success [27], including a strong PCP champion, on-site/accessible DCM, perceived financial security, engaged psychiatrist, and warm handoffs (physicians introduce patients to DCMs following a confirmed depression diagnosis). Other measures included number/training/licensure of DCMs, percentage of DCM and psychiatrist time spent in direct patient care, and adherence to weekly multidisciplinary case reviews. We also assessed practice size/setting, patient demographics, number/FTE of residents and attendings, and funding streams. We tailored interviews to interviewees' positions: DCM, administrator, PCP, and psychiatrist. We asked participants "what makes the program [i.e., OMH's Medicaid Reimbursement program] challenging," "what would make it better," "what are best practices," and the perceived effectiveness of $\mathrm{CC}$ in their clinics. Interviews were semi-structured with open-ended questions (see interview guide in Additional file 1). Information gathered focused on sites themselves, not their larger healthcare systems.

\section{Qualitative data analysis}

We analyzed data pertaining to sustainability barriers and facilitators using NVIVO qualitative research software package, version 11.1. To inform future interventions, we used thematic analysis, incorporating a data-driven inductive approach [28-30]. Two coders (N.M. and R.S.) independently coded all content for meaning and identified central themes [31, 32]. Preliminary codes guided text analysis and as new themes emerged, we assigned inductive codes to data segments [30]. We then compared codes by sustaining and opt-out status. We reconciled disagreements in consensus meetings. Kappa for agreement between coders was 0.84 .

\section{Results}

\section{Quantitative analyses}

\section{CC implementation metrics in clinics opting to enter the} sustainability phase vs. opting out

At the end of the 2-year implementation period, clinics opting to continue the program in the sustainability phase vs. opting out had higher median [interquartile range] care manager FTEs (1.00 [0.75] vs. $0.50[0], p=0.002)$ and achieved higher clinical improvement rates $(46.0 \%[53.0]$ vs. $7.5 \%$ [23.0], $p=$ $0.004)$. We found no significant differences $(p<0.05)$ in median rates of depression screening (96.5\% [13.0] vs. $87.0 \%$ [41.0], $p=0.51$ ), enrolled patients per calendar year $(43.0 \%$ [45.0] vs. $34.0 \%$ [13.0], $p=0.22)$, and psychiatric consultations per quarter among enrolled patients $(100 \%$ [44.0] vs. $90 \%$ [100], $p=0.53)$ (Table 1). Differences in clinic census (5669 [7635] vs. 2686 [1829], $p=0.06)$ and enrolled patients/DCM FTE (137.8 [89.0] vs. 58.0 [61.0], $p=0.07$ ) approached significance. Among the six opt-out clinics, reasons for opting out of the sustainability phase were "staffing" $(n=5)$ and billing infrastructure $(n=1)$.

Table 1 Implementation-end fidelity metrics in sustaining vs. opt-out clinics

\begin{tabular}{|c|c|c|c|}
\hline Metric (median, [IQR]) & $\begin{array}{l}\text { Sustaining clinics } \\
(n=26)\end{array}$ & $\begin{array}{l}\text { Opt-out clinics } \\
(n=6)\end{array}$ & $P$ value \\
\hline Total census at clinic & $5669[7635]$ & 2686 [1829] & 0.06 \\
\hline$\%$ screened per calendar year ${ }^{1}$ & $96.5 \%$ [13.0] & $87.0[41.0]$ & 0.51 \\
\hline Depression care manager full-time equivalent & $1.00[0.75]$ & $0.50[0]$ & 0.002 \\
\hline Number of participants enrolled/FTE ${ }^{2}$ & $137.8[89.0]$ & $58.0[61.0]$ & 0.07 \\
\hline$\%$ of depressed patients in calendar year enrolled into collaborative care program ${ }^{3}$ & $43.0 \%[45.0]$ & $34.0 \%[13.0]$ & 0.22 \\
\hline$\%$ currently enrolled in third quarter with psychiatry consultation ${ }^{4}$ & $100 \%[44.0]$ & $90 \%[100]$ & 0.53 \\
\hline$\%$ enrolled for 6 months and still on med/therapy $(\%)^{5}$ & $15.0 \%[21.0]$ & $42.0 \%[85.0]$ & 0.77 \\
\hline$\%$ of patients enrolled in collaborative care $\geq 16$ weeks with PHQ9 $<10^{6}$ & $46.0 \%[53.0]$ & $7.5 \%[23.0]$ & 0.004 \\
\hline
\end{tabular}

${ }^{1} \%$ unique adult patients per year from the outpatient site who received a PHQ-2 or PHQ-9 over number of patients

${ }^{2}$ Number of patients currently enrolled in collaborative care Quarter 3 per depression care manager Full Time Equivalent

${ }^{3} \%$ unique adult patients per year from the outpatient site screening positive for depression who enrolled in physical-behavioral health care coordination program (Collaborative Care Initiative) per year

${ }^{4} \%$ of unique adult patients enrolled in the Collaborative Care Initiative for which a psychiatric consultation occurred during this reporting period

${ }^{5} \%$ of unique adult patients enrolled in the Collaborative Care Initiative still receiving medication and/or psychotherapy six (6) months after enrollment

${ }^{6} \%$ unique patients enrolled in the Collaborative Care Initiative $\geq 16$ weeks whose PHQ- $9<10$

$p<0.05$ was considered statistically significant 


\section{CC metrics 1 and 2 years into sustainability among 26 sustaining clinics}

Compared to baseline, at 1 and 2 years into the sustainability phase (median [interquartile range]), sustaining clinics reported stable screening rates (88.5\% [19.0] vs. 86.0\% [31.0] and 91.0\% [18.0]) and DCM FTEs (1.00 [1.00] vs. 1.00 [1.00] and 2.00 [1.00]). They also saw stable median PHQ-9 (10.5 [5.0] vs. 9.75 [6.0] and 10.0 [3.0]) and percent enrolled $\geq 70$ days without improvement but with a psychiatry consult or treatment change rates (Table 2). Clinics reported improvements in the proportion of patients enrolled in CC with $\geq 3$ DCM contacts $(29.0 \%$ [33.0] vs. $24.0 \%$ [33.0] and 40.5\% [24.0]) and of patients enrolled $\geq 70$ days and in remission (33.0\% [22.0] vs. 49.0\% [25.0] and 58.0\% [19.0]). However, patient enrollment/FTE significantly decreased (56.0 [36.0] vs. 44.6 [18.0] and 36.5 [37.5]). The number of patients/FTE screening positive for depressive symptoms remained stable in the same period (297 [354] vs. 281 [204] and 337 [294]) (Table 1).

\section{Site visit characteristics and sustainability fidelity}

Eight site visits yielded 31 semi-structured interviews (7 psychiatrists, 8 clinic administrators, 8 PCPs, and 8 DCMs) (Fig. 1). We conducted 7 interviews at 2 opt-out sites (A and F) and 24 interviews at six sustaining sites; most interview participants (73\%) were female (Table 3 ). Sites were representative of the overall population: at the end of the implementation phase (2014), opt-out (vs. sustaining) sites participating in the qualitative interviews had fewer overall DCM FTEs (both $0.5-1$ vs. $\geq$ 1.0), fewer enrolled patients/DCM FTE (30-103 vs. 70179 ) and lower improvement rates (0-23\% vs. $14-66 \%$ in sustaining clinics).

\section{Clinic characteristics}

Overall, all clinics were part of larger healthcare systems, the majority of which had other clinics implementing $\mathrm{CC}$ through the $\mathrm{OMH} / \mathrm{DOH}$ program. All clinics had more resident (15-160 residents at 4-16 FTEs) than attending (6-26 attendings at 4-11 FTEs) PCPs. Opt-out clinics were slightly smaller clinics (i.e., cared for fewer patients) and had fewer overall PCP FTEs than sustaining clinics. Two participating clinics (B and $\mathrm{E}$ ) were public healthcare systems within $\mathrm{H}+\mathrm{H}$. All but one (opt-out) site cared for a majority Medicaid population.

\section{CC metrics and implementation fidelity in the sustainability period}

All clinics reported leadership support for $\mathrm{CC}$ and five of eight felt that the CC program was financially secure, though six of eight clinics (including both opt-out clinics), were using additional funding streams to cover extra costs in the sustainability phase. Fifty percent of all sites reported routine warm handoffs. All six sustaining sites reporting weekly psychiatry consults and imbedded psychiatrists who spent $20-75 \%$ of their time in direct patient care. These sustaining clinics also noted strong PCP champions, PCPs who routinely prescribed psychiatric medications and full support of PCPs for the program. Five of six sustaining sites had onsite DCMs and reported caseloads of $\geq 50$ patients/DCM FTE at the time of our interview. Four of six sites reported that care managers time spent $>50 \%$ of their time in patient sessions and reported investing additional resources in hiring a paraprofessional to assist the care manager in tasks such as registry upkeep (Table 3 ).

Meanwhile, both opt-out sites reported low psychiatry FTEs dedicated to the program (0 and 0.1 FTE) and $0 \%$ psychiatrist time spent in direct patient care. These opt-out sites reported no weekly psychiatry meetings with care managers, lacked PCP champions and both reported care manager caseloads of $<50$ patients/FTE and that care managers spent only $50 \%$ of their time in direct patient care. Neither had paraprofessionals and 1 reported that PCPs were not routinely prescribing psychiatric medications (Table 3 ).

\section{Barriers to CC implementation in the sustainability phase (themes are bolded, sub-themes are underlined and italicized)}

Time-personnel resources (74\% of respondents; $71 \%$ at sustaining clinics and $86 \%$ at opt-out clinics). Interviewees noted inadequate number of DCMs (46\% sustaining vs. $71 \%$ opt-out) to meet clinical demands as well as competing DCM roles (13\% sustaining vs. $29 \%$ opt-out) in clinics (e.g., registry upkeep). Respondents also described inadequate $M D$ resources, though sustaining sties particularly noted competing PCP demands and time constraints: "[Providers] are getting hammered with increased number of items they are supposed to manage in the visit. We have to screen every patient for risk of domestic violence...falls" (Sustaining PCP) while opt-out clinics focused on lack of psychiatry resources "case consultation with psychiatrist didn't happen. Psychiatrist available by telephone for consultation, but no set time to have him available. If you are in a crisis to call a psychiatrist this is ok, but overall not" (Opt-out PCP). Other factors included inadequate space and psychosocial resources, as well as inadequate personnel-resources in general (e.g., some clinics did not adequately plan and think through logistics, personnel to patient ratios, and FTEs) (Table 4; Fig. 2).

Patient engagement (61\% of respondents; $67 \%$ sustaining and $43 \%$ opt-out) was another major barrier to CC sustainability, corresponding to quantitative findings of decreasing enrollment rates, particularly relevant to sustaining clinics attempting to sustain $\mathrm{CC}$ and bill for patients through the program. Respondents described high 


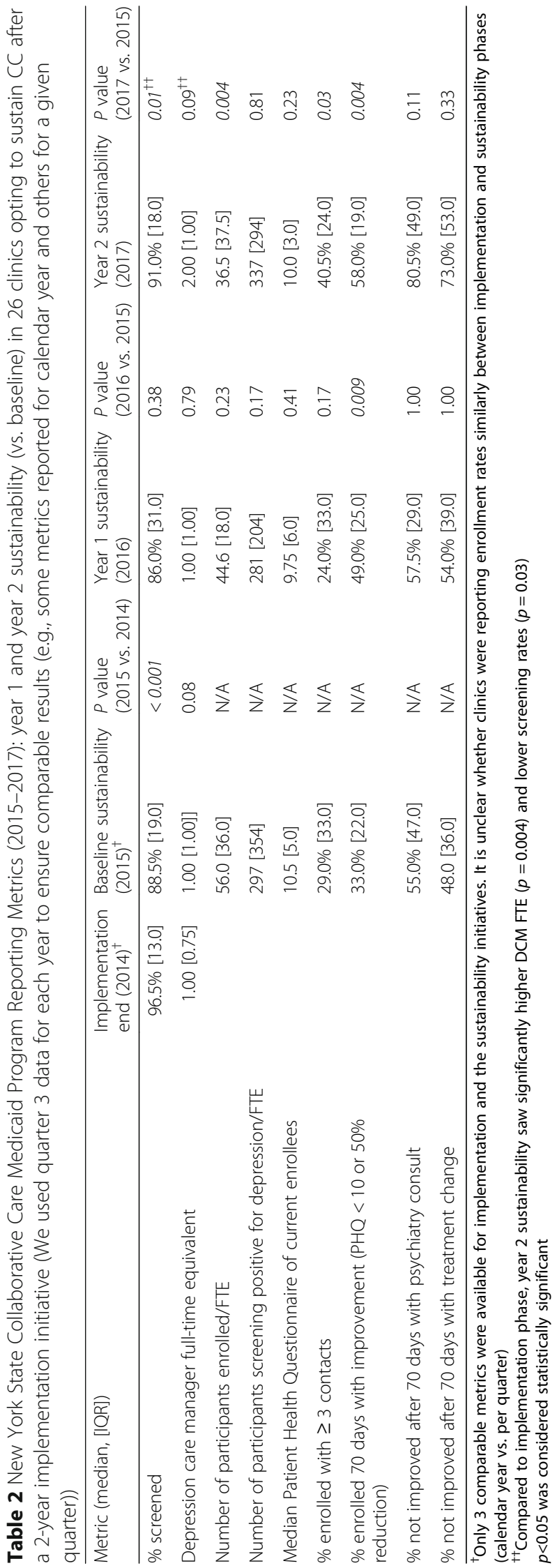


Table 3 Clinic-level characteristics and implementation-related outcomes of 8 sites participating in the New York State Collaborative Care program in sustainability phase (gray=opt-out clinics)

\begin{tabular}{|c|c|c|c|c|c|c|c|c|c|}
\hline & & $\mathbf{A}$ & B & $\mathbf{C}$ & D & $\mathbf{E}$ & $\mathbf{F}$ & $\mathbf{G}$ & $\mathbf{H}$ \\
\hline \multirow{7}{*}{$\begin{array}{l}\text { Implementation } \\
\text { Fidelity/ } \\
\text { Outcomes } \\
(\mathbf{2 0 1 4 )}\end{array}$} & Depression screening/calendar year $(\%)^{1}$ & $99 \%$ & $73 \%$ & $86 \%$ & $94 \%$ & $89 \%$ & $57 \%$ & $62 \%$ & $88 \%$ \\
\hline & Dedicated depression care manager (FTE) & 1.0 & 0.7 & 2.0 & 1.8 & 1.0 & 0.2 & 2.2 & 1.2 \\
\hline & \# CC patients currently enrolled/FTE ${ }^{2}$ & 103 & 179 & 133 & 91 & 216 & 30 & 70 & 150 \\
\hline & Depression screens/yr. enroll in CC $(\%)^{3}$ & $25 \%$ & $25 \%$ & $18 \%$ & $32 \%$ & NR & $38 \%$ & $13 \%$ & NR \\
\hline & Enrolled w/ psych consult $(\%)^{4}$ & $100 \%$ & $56 \%$ & $100 \%$ & $100 \%$ & $27 \%$ & $80 \%$ & $87 \%$ & $100 \%$ \\
\hline & Enrolled and on med/therapy $x 6 \mathrm{mo}(\%)^{5}$ & $0 \%$ & $69 \%$ & $2 \%$ & $17 \%$ & $24 \%$ & $84 \%$ & $0 \%$ & $0 \%$ \\
\hline & Enrolled $\geq 16$ weeks with PHQ $9<10(\%)^{6}$ & $0 \%$ & $66 \%$ & $14 \%$ & $48 \%$ & $38 \%$ & $23 \%$ & $20 \%$ & $44 \%$ \\
\hline \multirow{7}{*}{$\begin{array}{c}\text { Clinic } \\
\text { Characteristics } \\
(2015-2016)\end{array}$} & Yearly clinic census & $<10 \mathrm{~K}$ & $10 \mathrm{~K}-25 \mathrm{~K}$ & $10 \mathrm{~K}-25 \mathrm{~K}$ & $25 \mathrm{~K}+$ & $<10 \mathrm{~K}$ & $<10 \mathrm{~K}$ & $10 \mathrm{~K}-25 \mathrm{~K}$ & $<10 \mathrm{~K}$ \\
\hline & Part of larger health system? & Yes & Yes & Yes & Yes & Yes & Yes & Yes & Yes \\
\hline & Other clinics in system implementing CC & Yes & Yes & Yes & Yes & Yes & No & Yes & Yes \\
\hline & Medicaid recipients (\%) & $63 \%$ & $70 \%$ & $35 \%$ & $50 \%$ & $63 \%$ & $10 \%$ & $48 \%$ & $65 \%$ \\
\hline & Leadership committed to the program & Yes & Yes & Yes & Yes & Yes & Yes & Yes & Yes \\
\hline & PCP residents/attendings and NPs (FTE) & $4.2 / 8$ & $16 / 12 / 4$ & $8 / 10.7$ & $7.1 / 11.4$ & NR & $\mathrm{NR} / 2$ & NR & $5 / 5.5$ \\
\hline & \#Residents/Attendings/Nonteaching & NR & $140 / 26 / 5$ & 40 PCPs & $55 / 23 / \mathrm{NR}$ & $160 / 21 / \mathrm{NR}$ & $17 / 2 / \mathrm{NR}$ & $30 / 20 / 10$ & $15 / 6 / 1$ \\
\hline \multirow{17}{*}{$\begin{array}{l}\text { Fidelity and } \\
\text { Consistency of } \\
\text { CC Delivery in } \\
\text { Sustainability } \\
(2015-2016)\end{array}$} & Perceived financial health/security & Adeq & Inadeq & Adeq & Adeq & Adeq & Inadeq & Adeq & Inadeq \\
\hline & $\begin{array}{l}\text { cover extra costs } \\
\text { collo }\end{array}$ & Yes & Yes & Yes & Yes & Yes & Yes & No & No \\
\hline & Psychiatrist (FTE) & 0 & 0.75 & 0.5 & 0.6 & 0.5 & 0.1 & 0.1 & 0.2 \\
\hline & Depression Care manager (FTE) & 1.0 & 2.0 & 1.0 & 2.5 & 2.0 & 0.5 & 2.0 & 1.0 \\
\hline & Licensing of care manager & BA & LCSW & Psych NP & $\mathrm{RN} / \mathrm{LCSW}$ & LCSW & LCSW & LMSW & LCSW \\
\hline & Additional paraprofessional roles (FTE) & 0 & 0.5 & 1.0 & 1.0 & 1.0 & 0 & 0 & 0 \\
\hline & $\begin{array}{l}\text { Caseload per care manager FTE in } \\
\text { program at the time of interview }{ }^{2} \\
\text { Psychiatrist met with care manager }\end{array}$ & $30-40$ & $50-60$ & 120 & $40-50$ & $8-44$ & $35-40$ & $65-67$ & $50-60$ \\
\hline & weekly. & No & Yes & Yes & Exceeded & Yes & No & Yes & Yes \\
\hline & Psychiatrist time in direct patient care (\%) & $0 \%$ & $75 \%$ & $20 \%$ & $64 \%$ & $50 \%$ & $0 \%$ & $50 \%$ & $75 \%$ \\
\hline & Strong PCP champion(s). & No & Yes & Yes & Yes & Yes & No & Yes & Yes \\
\hline & $\begin{array}{l}\text { PCPs routinely prescribe psychiatric } \\
\text { medications. }\end{array}$ & No & Yes & Yes & Yes & Yes & Yes & Yes & Yes \\
\hline & Most PCPs support program/refer patients. & No & Yes & Yes & Yes & Yes & Yes & Yes & Yes \\
\hline & Onsite care manager. & Yes & Yes & No & Yes & Yes & Yes & Yes & Yes \\
\hline & Care managers perceived as strong. & Mixed & Mixed & Yes & Yes & Yes & Yes & Mixed & Yes \\
\hline & $\begin{array}{l}\text { Routine warm handoffs to care manager } \\
(>50 \% \text { of referrals }) \text { ? }\end{array}$ & No & No & No & Yes & Yes & Yes & Yes & No \\
\hline & Care manager time in patient sessions $(\%)$ & $50 \%$ & $85 \%$ & $85 \%$ & $50 \%$ & $90 \%$ & $50 \%$ & $33 \%$ & $60 \%$ \\
\hline & Communicate with patients via text/email. & No & No & No & Yes & No & No & Rare & No \\
\hline \multirow{6}{*}{$\begin{array}{c}\text { Sustainability } \\
\text { fidelity/ } \\
\text { Outcomes (2017) }\end{array}$} & Depression screening/calendar year $(\%)^{1}$ & N/A & $92 \%$ & $84 \%$ & $98 \%$ & $63 \%$ & N/A & $76 \%$ & $78 \%$ \\
\hline & Depression Care manager (FTE) & N/A & 2.0 & 1.0 & 2.5 & 2.0 & N/A & 2.0 & 1.0 \\
\hline & \# CC patients currently enrolled/FTE ${ }^{2}$ & $\mathrm{~N} / \mathrm{A}$ & 67 & 54 & 51 & 34 & N/A & 11 & 63 \\
\hline & $\begin{array}{l}\text { Enrolled not improving w/ psych consult } \\
(\%)^{7}\end{array}$ & N/A & $53 \%$ & $88 \%$ & $96 \%$ & $95 \%$ & N/A & $0 \%$ & $100 \%$ \\
\hline & $\begin{array}{l}\text { Enrolled not improving } \mathrm{w} / \text { treatment } \\
\text { change }(\%)^{8}\end{array}$ & N/A & $41 \%$ & $76 \%$ & $78 \%$ & $73 \%$ & N/A & $33 \%$ & $100 \%$ \\
\hline & PHQ $9<10$ or by $50 \%$ in $\geq 10$ weeks ${ }^{9}$ & N/A & $52 \%$ & $42 \%$ & $61 \%$ & $49 \%$ & $\mathrm{~N} / \mathrm{A}$ & $44 \%$ & $59 \%$ \\
\hline
\end{tabular}

LCSW licensed social worker, BA Bachelor of Arts, Psych NP psychiatric nurse practitioner, FTE full-time equivalent, PHQ9 Patient Health Questionnaire, CC collaborative care, $R N$ registered nurse

${ }^{1} \%$ unique adult patients per year from the outpatient site who received a PHQ-2 or PHQ-9 over number of patients

${ }^{2}$ Number of patients currently enrolled in collaborative care Q3 per depression care manager FTE (there may have been variations in how clinics reported these from implementation to sustainability).

${ }^{3} \%$ unique adult patients per year from the outpatient site screening positive for depression who enrolled in physical-behavioral health care coordination program (Collaborative Care Initiative) per year

${ }^{4} \%$ of unique adult patients enrolled in the Collaborative Care Initiative for which a psychiatric consultation occurred during this reporting period.

${ }^{5}$ Number of unique adult patients enrolled in the Collaborative Care Initiative still receiving medication and/or psychotherapy six (6) months after enrollment

${ }^{6} \%$ unique patients enrolled in the Collaborative Care Initiative $\geq 16$ weeks whose PHQ- $9<10$

$7 \%$ of patients enrolled 70 days and not improved who received a psychiatric consultation during this reporting period

${ }^{8} \%$ of patients enrolled 70 days and not improved who received a treatment change during this reporting period

${ }^{9} \%$ of patients enrolled 70 days (10 weeks) with PHQ9 $<10$ or PHQ9 reduced by $50 \%$

no-show rates and poor completion of problem-solving therapy homework (patient non-adherence; $42 \%$ sustaining and $29 \%$ opt-out) which contributed to long-waiting lists and delayed care. Respondents also described reluctance to enter treatment due to stigma as well as poor health literacy and cultural misconceptions of depression and its treatment (culture-language; $13 \%$ sustaining vs. $29 \%$ opt-out). Language barriers also made it complicated to hire DCMs: "[it was] hard to recruit someone who spoke language, used language lines (had to pull staff to translate)" (Opt-out Admin). Patient engagement closely related to infeasible warm handoffs (19\% of respondents): "[we had a] part time care manager who can't have [time for] a warm handoff [which] is much less effective" (Sustaining DCM). 
Noise et al. Implementation Science (2018) 13:128

Page 8 of 17

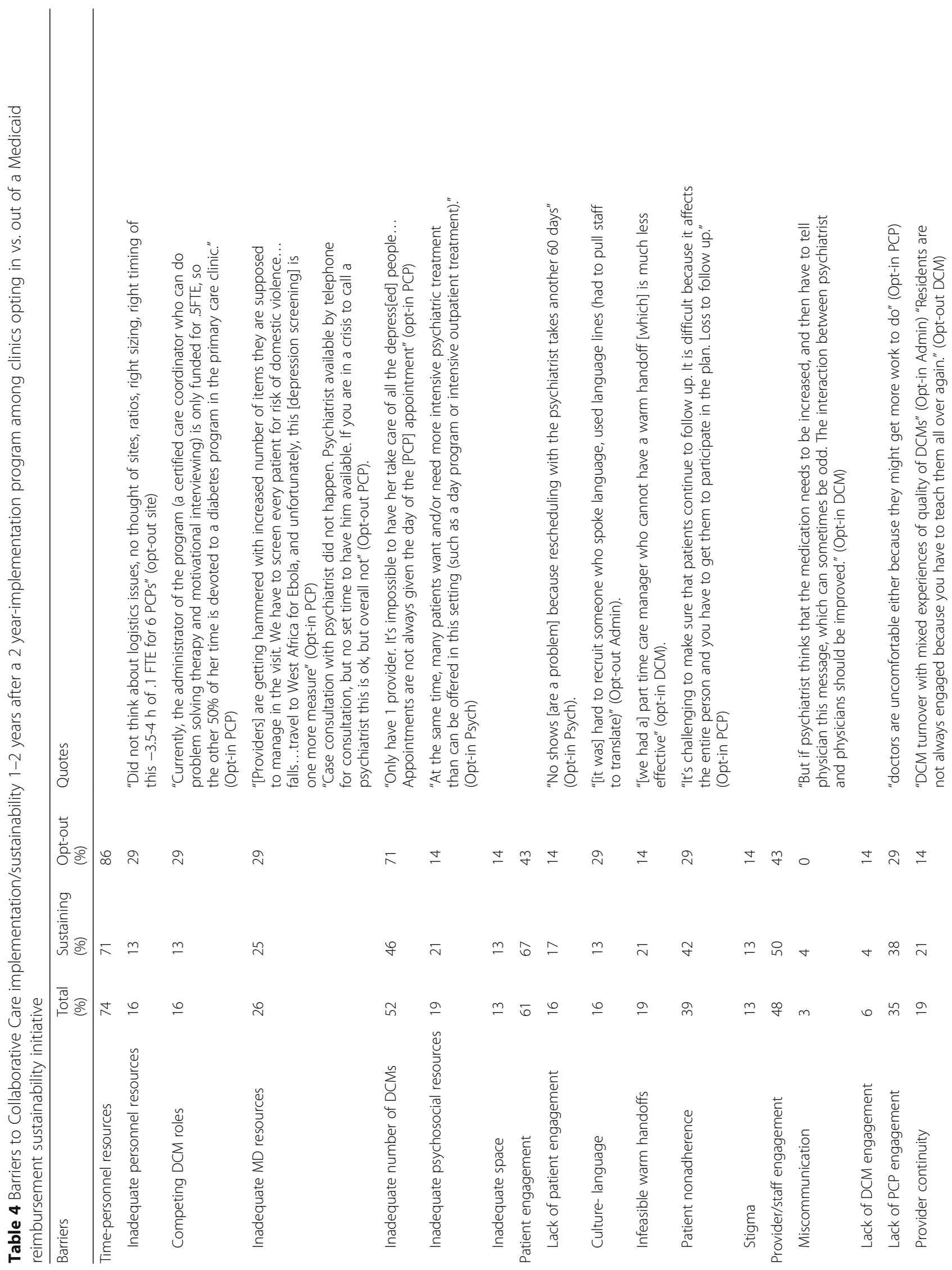


Noise et al. Implementation Science (2018) 13:128

Page 9 of 17

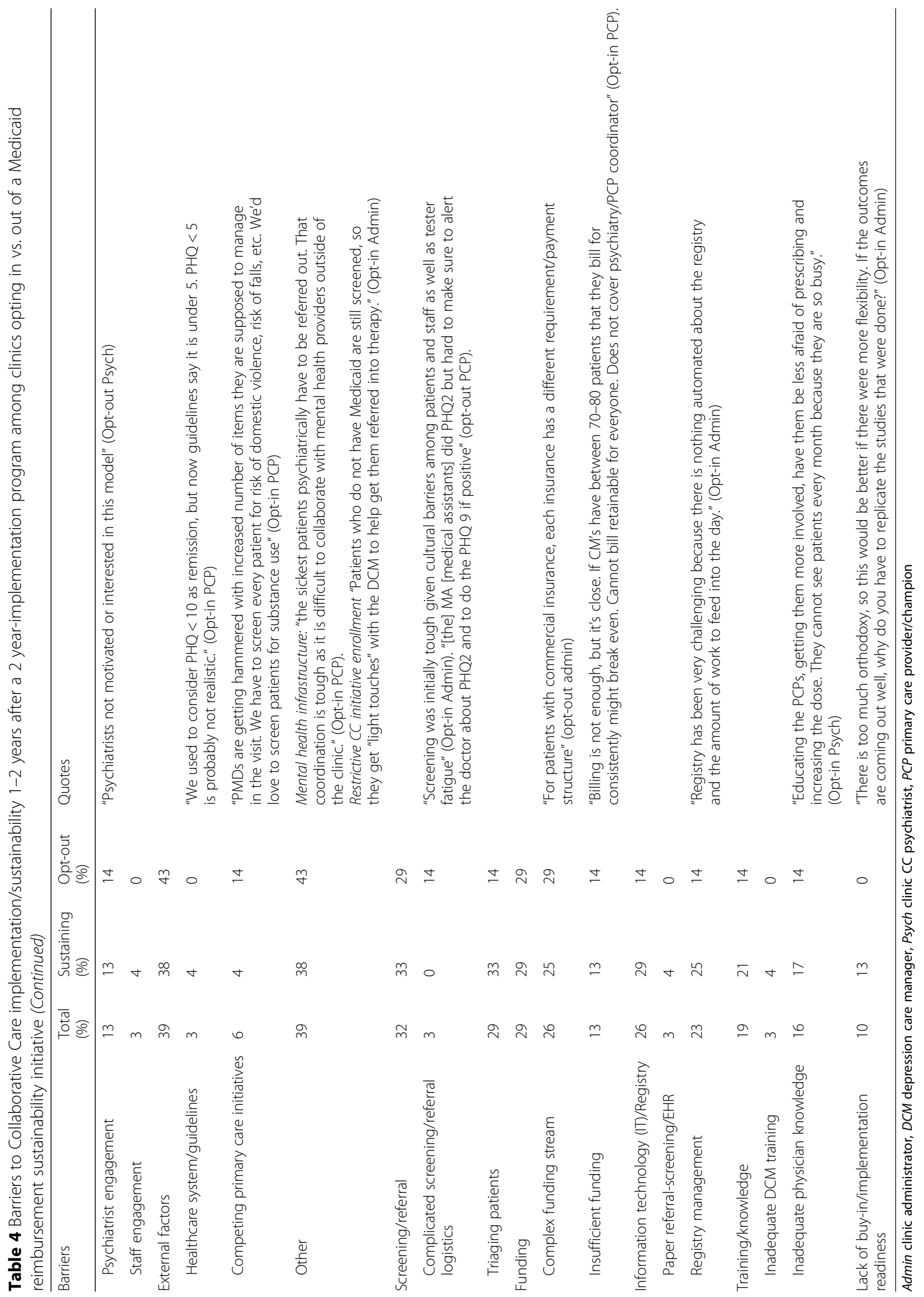




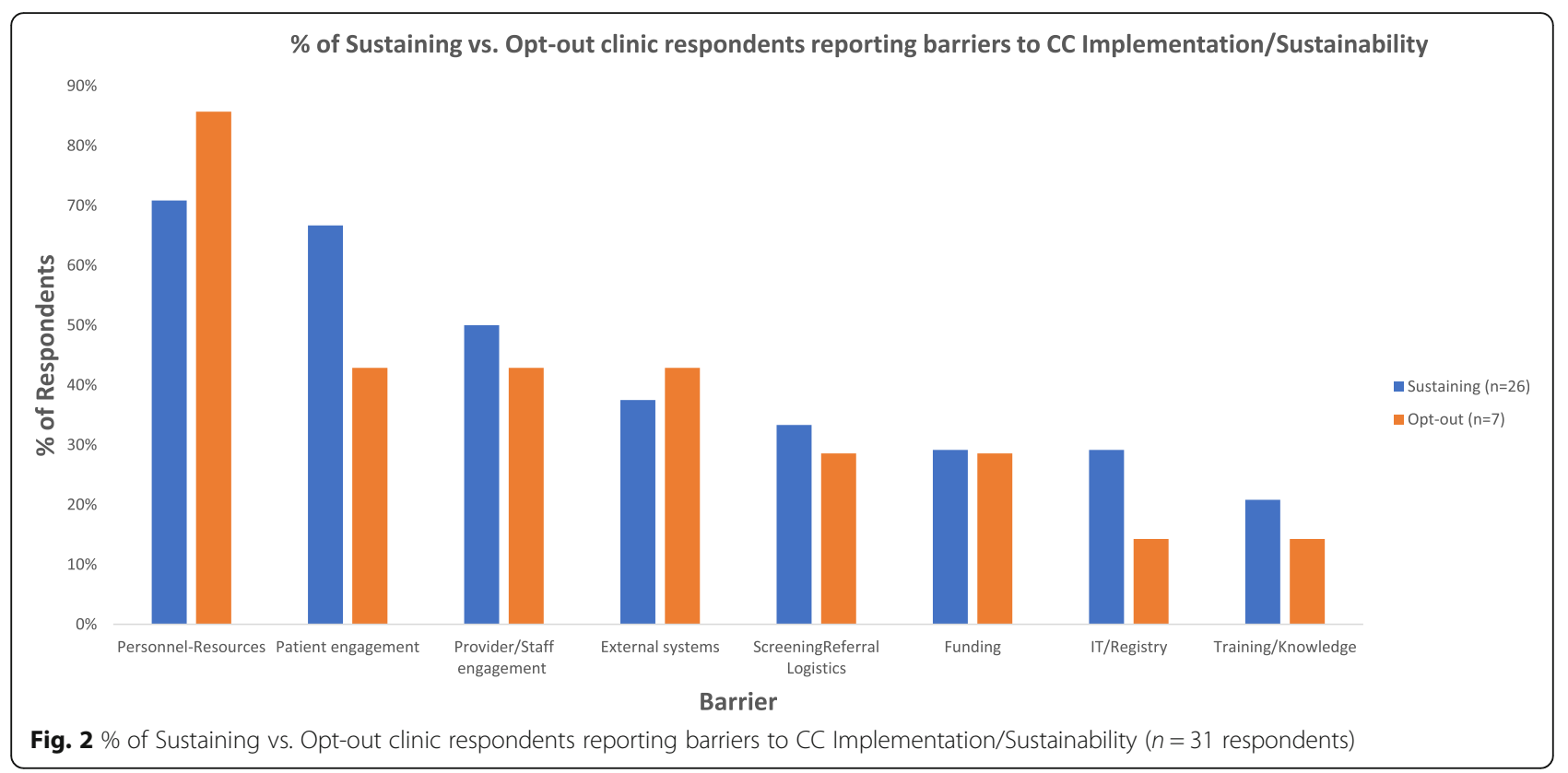

Provider/staff engagement (i.e., staff, PCP, DCM, and psychiatrist engagement and communication as well as provider continuity; $48 \%$ of respondents; $50 \%$ sustaining, $43 \%$ opt-out). Respondents described miscommunication between psychiatry and PCPs: "But if psychiatrist thinks that the medication needs to be increased, and then has to tell [the] physician this message, [then this exchange] can sometimes be odd. The interaction between psychiatrist and physicians should be improved." (Sustaining DCM). One sustaining DCM also noted, "Doctors are uncomfortable either because they might get more work to do" (PCP engagement). In addition, hiring and maintaining fully committed DCMs and psychiatrists for a primary care initiative often proved difficult (provider continuity): "[we] supervise the social workers more than psychiatrists due to turnover of the psychiatrists (have had 6 psychiatrists over 3 years)" (Sustaining PCP). Resident turnover also made program fidelity difficult $(10 \%$ of respondents specifically noted resident engagement or training/knowledge as barriers).

External environment (39\% of respondents; 38\% sustaining and 43\% opt-out) also appeared to affect sustainability. Participants mentioned competing primary care initiatives, such as Accountable Care Organizations (ACOs), which often had their own metrics that either added to providers' workload or did not align with OMH's required metrics. Other external factors included the mental health infrastructure as a whole: "the sickest patients psychiatrically have to be referred out. That coordination is tough as it is difficult to collaborate with mental health providers outside of the clinic." (Sustaining $\mathrm{PCP}$ ) and restrictive enrollment requirements (i.e., clinics could only receive the $\$ 150$ per-member per-month supplemental payment for Medicaid patients only): "Patients who do not have Medicaid are still screened, so they get "light touches" with the DCM to help get them referred into therapy" (Sustaining Admin).

Workflow logistics (32\% of respondents; 33\% sustaining and $29 \%$ opt-out) barriers related to complicated screening and referral and triaging, which included conducting confidential screening, alerting physicians to depression scores, completing a warm handoff, and convincing patients to enroll. Sustaining interviewees (33\%) noted difficulty with screening fatigue while opt-out clinics (29\%) reported difficulties around consistency of CC delivery "[the] MA [medical assistants] did PHQ2 but hard to make sure to alert the doctor about PHQ-2 and to do the PHQ-9 if positive" (Opt-out PCP).

Funding (30\% of respondents; 29\% sustaining and 17\% opt-out). Interviewees (mostly administrators) remarked on complex funding streams. For sustaining clinics, to collect the 25\% "retainage" (fee-for-quality), payment practices had to implement a system of quality metrics, which required time and resources. In addition, participants described difficulty using $\mathrm{OMH} / \mathrm{DOH}$ specific rate codes for $\mathrm{CC}$, not recognized by some electronic health records (EHRs) and often submitted manually. Nonetheless, interview participants noted that this $\mathrm{OMH} / \mathrm{DOH}$ sponsored program proved essential given NYS restrictions that prohibit social workers from billing for most patients. Opt-out sites cited complex billing infrastructure: "for patients with commercial insurance, each insurance has a different requirement/payment structure" (Opt-out Admin) as well as insufficient numbers of Medicaid patients to make opting into the Medicaid reimbursement program appealing. There were also concerns about insufficient funding for all program components: "Billing is not 
enough, but it's close. If CM's have between 70-80 patients that they bill for consistently might break even. Cannot bill [sustainably] for everyone. Doesn't cover psychiatry/ PCP coordinator" (Sustaining PCP).

With the training and accountability provided by this initiative, fewer individuals remarked on barriers related to information technology/registry (IT, specifically registry management, screening) (26\%), training/knowledge $(19 \%)$, or buy-in/implementation readiness (10\%) (Fig. 2).

\section{Facilitators to CC implementation in the sustainability phase}

Patient engagement (81\% of respondents; 79\% sustaining and $86 \%$ opt-out) was the most cited facilitator, specifically the use of personalization/education/motivation (i.e., message framing, patient preference driven treatment, motivational interviewing, success stories, targeted/tailored psychoeducation). Respondents also emphasized the importance of warm handoffs, i.e., PCPs' real-time introduction of the patient to DCMs: "[When you perform] warm handoffs, then many more [patients] follow up, maybe 80\%" (DCM). Respondents also recommended finding DCMs proficient in engagement, reminder systems, and appointment flexibility (Table 5, Fig. 3).

Provider/staff engagement (77\% of respondents; $71 \%$ sustaining, 100\% opt-out). Participants recommended improving provider/staff communication by creating mini inter-disciplinary teams, engaging staff and PCPs: (e.g., "Scripting to the PCPs that this will help your panel look better."-Sustaining DCM) and optimizing use of psychiatry: " $50 \%$ face to face visits, $50 \%$ for chart reviews, case supervision with team..." (Sustaining Admin).

Personnel resources (71\% of respondents; $75 \%$ sustaining, 57\% opt-out). Most clinics noted the need for either additional or replacement DCMs and psychiatrists 12 years into the sustainability period. Respondents, particularly sustaining clinics recommended hiring paraprofessionals to complete administrative tasks (67\% sustaining vs. 0\% opt-out): "[Our] patient educator [i.e., paraprofessional] allows the social worker to practice at [the] top of [her] license: [she can make] appointment reminders, check in on treatment care goals, scheduling, in between CM appointment contact... [She also] makes sure [the] patient fills new prescriptions [and] takes meds... [she also] helps monitor the registry" (Sustaining Admin).

Screening/referral (52\% of respondents; $58 \%$ sustaining, 29\% opt-out). Respondents recommended flexibility/quality improvement initiatives and standardization: Successful sustaining sites developed protocols for medication management to help providers at the time of referral: "[We] developed a protocol for medication management for depression, which is VERY prescriptive,...90\% of the time that people do not achieve remission is because they have not followed the protocol carefully" (Sustaining Admin).

Training (55\% of respondents; 50\% sustaining, 71\% opt-out). Participants emphasized the need for ongoing training "A coach teaches care managers engagement [strategies] and [staff] how to get an accurate PHQ score... [there is also] training in motivational interviewing... quarterly training...certification is intensive" (Sustaining DCM). Respondents recommended incorporating training into workflow/schedules of staff, residents, attendings, and care managers: "Involve ALL of the staff, including support staff (nurses, MAs, clerical staff) because it is a culture transformation...Repetition was also very important" (Opt-out Admin).

IT/Registry (45\% of respondents; $46 \%$ sustaining and $43 \%$ opt-out): Respondents emphasized incorporating IT staff into the model: "IT person is mandatory for data collection, data analysis, and EHR updates with alerts or other changes to both be user friendly and meet the needs." (Opt-out Admin). Other facilitators included leveraging telemedicine/psychiatry e-consults, internet-based dashboards/mobile technology for screening and teaching and optimizing EHR for referral, metric tracking and automating registry entry: "If PCP has a question that involves psychiatric med management (NOT a diagnostic question), they use EPIC to send a message to the care manager. Each week they sit down with the psychiatrist for $10-12 \mathrm{~min} /$ consult to review chart and make multiple recommendations. These are primarily bipolar disorder or more complex patients, which has reduced face to face encounters by $>50 \%$." (Sustaining Admin).

External factors (45\% of respondents; $42 \%$ sustaining and $57 \%$ opt-out). Respondents felt the healthcare system's reimbursement infrastructure needed improvement as a whole: “A lot of systems don't credential SW's to bill. So coming up with a more streamlined approach to SW billing for hospital systems so that they have an incentive to do it." (Sustaining PCP). In addition, leadership commitment, optimizing long-term/community mental health options, and leveraging national/primary care initiatives were other important external factors, particularly for opt-out clinics.

Funding (32\% of respondents; 33\% sustaining and $29 \%$ opt-out). Respondents recommended leveraging current funding streams, remarking that the initial 2-year CC implementation program was integral to "roll[ing] out PCMH model and hir[ing] a part-time LCSW." (Opt-out Admin). The current $\mathrm{OMH} / \mathrm{DOH}$ program reimburses for Medicaid participants to meet billing limitations for Medicaid services provided by social workers. Sustaining clinics in particular noted that this initiative helped them sustain the program: "All funding is coming through $\mathrm{OMH}$ per member per month program. If care 


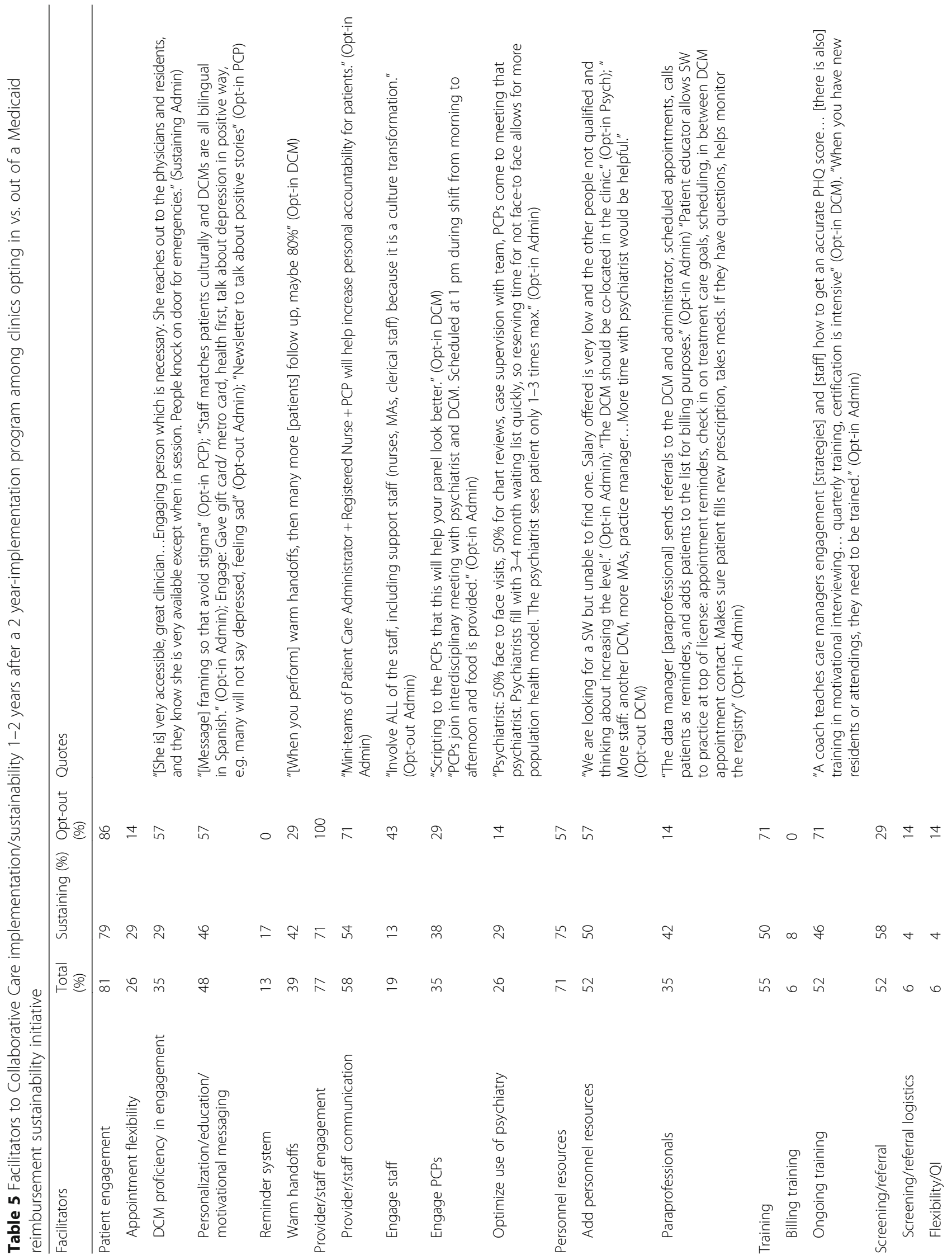


Noise et al. Implementation Science (2018) 13:128

Page 13 of 17

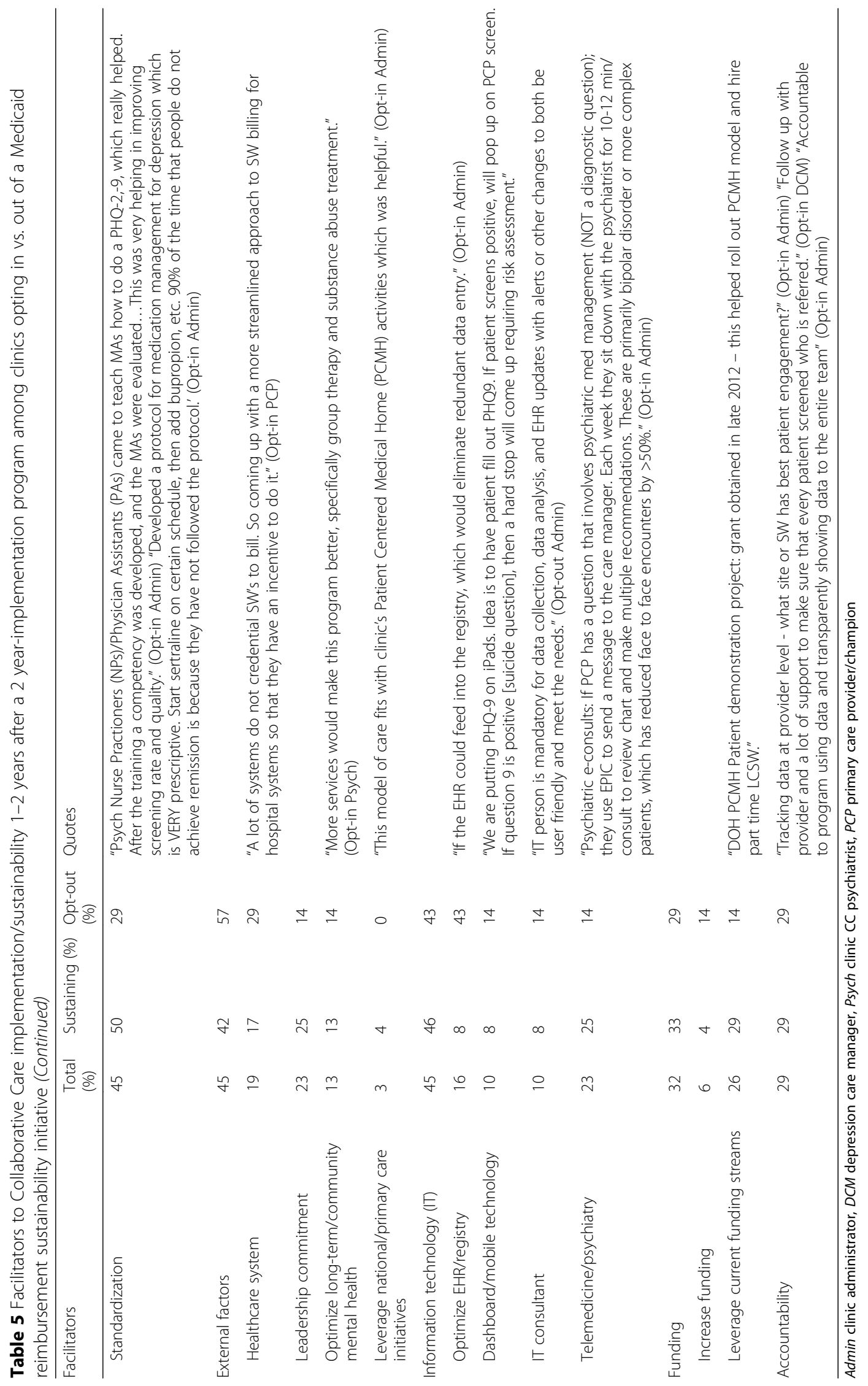


manager has caseload of at least 50 patients they can cover the program. We think this works so much so that we have applied for a 3rd Care manager." (Sustaining Admin). Respondents also emphasized increased funding to hire more care managers and staff (Fig. 3 ).

Accountability (29\% for all). One theme that appeared to be a facilitator for multiple other themes (i.e., provider/staff engagement, patient engagement, training, screening/referral) was around creating accountability though audit and feedback: "Transparency/Accountability [are key]: [We] share the data with the staff without names. They try to make it a little fun/mildly competitive but only once people had bought in. Physicians asked for it [the data] anyway because they were invested in it" (Opt-out Admin).

\section{Discussion}

Training programs with financial incentives improve sort-term CC implementation fidelity, as demonstrated by initiatives like the DIAMOND program [17] and the NYS $\mathrm{OMH} / \mathrm{DOH} \mathrm{CC}$ Initiative [33]. We add to the literature by describing $\mathrm{CC}$ processes that promote and inhibit implementation fidelity up to 5 years after initial implementation in a sample of 32 primary care clinics with academic affiliations (defined as serving as a training site for least 1 resident). We found that structural rules (e.g., payment reform) enacted by NYS encouraged most (81\%) but not all primary care clinics to continue beyond the $\mathrm{CC}$ implementation phase into the sustainability phase. Clinics that saw early clinical improvements and who invested in staffing FTEs were more likely to elect to enter the sustainability phase. Sustaining clinics went on to see stable depression screening rates and treatment titration rates, percentage of patients screening positive for depression, improved DCM contacts/patient and remission rates, and decreased CC enrollment rates/FTE 1 and 2 years into the sustainability phase. Sustaining clinics also maintained high CC fidelity, while clinics that opted-out clinics reported fewer psychiatry and care manager FTEs and patient caseloads/DCM FTE, less psychiatry and care manager time spent in direct patient care, and a lack of PCP champions. Respondents from both sustaining and opt-out clinics revealed that patient and provider engagement and care manager resources were critical factors to ensuring sustainability. Respondents mentioned barriers cited in prior implementation efforts, such as funding, training, workflow logistics, and leadership support factors, less often.

Payment reform alone was not enough to encourage all clinics to continue to provide CC. Respondents surveyed noted that implementation required considerable buy-in from staff and administration, time and resources. In fact, most sites interviewed used multiple funding streams to support CC. Opt-out clinics were often smaller than sustaining clinics and may have lacked the staffing flexibility (e.g., DCM FTEs) to assign staff part-time where needed to make the program successful. Opt-out sites also frequently reported a lack of PCP champions and engaged psychiatrists during the sustainability phase, both shown to correlate with patient activation and remission rates in CC. Relatedly, opt-out clinics tended to be those that did not see early clinical benefits for clients, and hence may not have seen value in continuing the program.

Sustaining and opt-out clinics reported similar barriers, such as lack of resources (e.g., care managers,

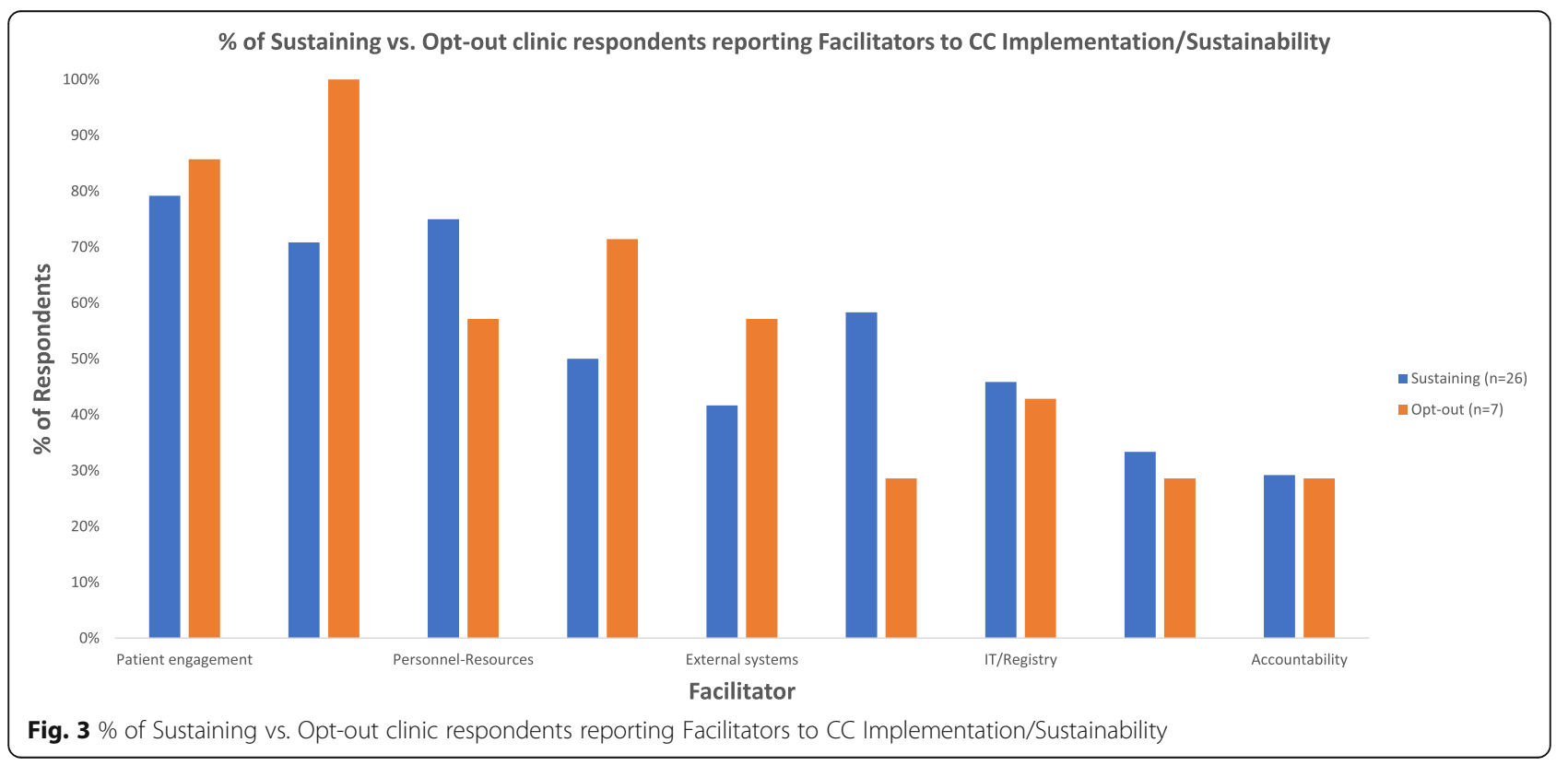


time) and poor patient and provider engagement in the sustainability phase. Our results are supported by another qualitative analysis of a depression and diabetes CC sustainability program, which identified patient medication concerns, provider concerns around psychotherapy, workloads of staff, and resource barriers [34]. These barriers may accrue over time and become particularly challenging as initial champions of the program turn over. Interest in the program and adherence to key engagement interventions like warm handoffs (only half of site reported routine use) may decline over time. This implementation drift may undermine the very activities that are necessary to generate the visits and associated billings needed to sustain the program.

Respondents identified several factors critical to addressing these barriers to sustaining CC. Patient engagement may respond to behavioral interventions, such as message framing and motivational interviewing ideally delivered via warm handoffs. Ongoing training and accountability [35] (i.e., feedback to providers about their own CC fidelity metrics or patient outcomes) may target provider engagement. Meanwhile, leveraging e-consults may improve psychiatry involvement. Restricted fiscal incentives (applied only to clients with Medicaid) on the other hand may have contributed to some clinics' decisions to opt-out. Finally, to address resource barriers, many of the sustaining clinics invested in lower-cost administrative assistants to free DCMs to engage in services that are more billable. These assistants also often performed warm handoffs. Our data cannot speak to whether having non-clinical staff perform this role helped or hindered engagement. However, research shows that task shifting may be associated with suboptimal long-term engagement rates and outcomes in mental health [36]. Warm handoffs between PCPs and DCMs correlate with improved remission rates in CC [27], and future research is needed to elucidate how best to incorporate paraprofessionals into the model.

Finally, the focus on healthcare systems with academic affiliations limits the generalizability of these findings. Healthcare systems where residents are trained may have resources not available to nonacademic institutions [22, 24]. Still, many clinics do participate in resident training, and the current sample of clinics is diverse with respect to size and ownership (the majority were public health systems or were community settings with academic affiliations), adding to the generalizability of our findings. In addition, only $10 \%$ of all respondents mentioned barriers specifically related to residents.

\section{Limitations}

There were several limitations in this study. We were only able to analyze long-term metrics in 26 of the 32 clinics due to missing data (i.e., opt-out clinics stopped collecting/reporting metrics), relied on descriptive statistics, and were unable to compare metrics to previously published early implementation period metrics due to a change in how we defined metrics. The sustainability intervention was not randomized, further limiting conclusions on effectiveness. However, our mixed methods approach allowed for a granular exploration of clinics successful and unsuccessful in sustaining CC. While we used a purposive approach for qualitative analyses to be representative of all 32 clinics in the initiative and stopped due to saturation, it is possible that we did not fully capture variations, barriers and facilitators across all clinics and furthermore, that participants conflated implementation and sustainability factors. We were underpowered to differentiate the number of barriers and facilitators mentioned by sustaining vs. opt-out sites, and did not employ process evaluation frameworks to better elucidate contextual factors. Finally, primary care clinics affiliated with academic systems limited the generalizability of our results, though they were diverse in size and ownership. The sample size, however, limited analysis of differences by ownership. Nonetheless, this study adds a rarely seen granular view of a large sustainability initiative.

\section{Conclusion}

$\mathrm{OMH}$ demonstrated its ability to aid clinics in meeting key domains of integrated care and advancing along the integrated care continuum [37]. Our findings suggest that measurement-based reimbursement programs are a successful strategy for sustaining CC in most but not all clinics. Clinics that saw early clinical improvement and invested in staffing FTEs were more likely to elect to enter the sustainability phase. While limited to settings where residents are trained, our results suggest that successful sustaining of CC may hinge on supporting practices that promote both patient and provider engagement and adequate care manager resources.

\section{Additional file}

Additional file 1: Interview guide: Entire interview guide. (PDF $96 \mathrm{~kb}$ )

\section{Abbreviations}

CC: Collaborative care (integration of primary care and mental health care programs); DCM: Depression care manager (often a social worker trained in providing therapy and integrated in the primary care setting); DOH: Department of Health (New York State's Department of Health); FTE: Full-time equivalent (hours worked by one employee on a full-time basis); OMH: Office of Mental Health (New York State's agency for mental health); PCP: Primary care physician (the primary medical provider for a patient in the primary care setting); PHQ: Patient Health Questionnaire (validated depression screening)

\section{Acknowledgements}

Dr. Siqin Ye and Ms. Jane Lowers contributed to copy editing this article. Danielle Chapman provided the data and metric definitions for analyses. 
Karina Davidson provided general support and mentorship as the executive director of the Center for Behavioral Cardiovascular Health.

\section{Funding}

This work was supported by funds from the Office of Mental Health Policy Scholar Program and National Institutes of Health (3 R01 HL114924-03S1; 1R01HS025198; R25HL126146). The NIH had no role in the design and conduct of the study, including the collection, management, analysis, interpretation of the data, preparation, review or approval of the manuscript, and decision to submit the manuscript for publication.

\section{Availability of data and materials}

The datasets used and/or analyzed during the current study are available from the corresponding author on reasonable request.

\section{Authors' contributions}

NM had full access to all the data in the study and takes responsibility for the integrity of the data and the accuracy of the data analysis. NM, RNS, SE, $\mathrm{AJ}$, and LS contributed to the study concept and design. NM and RNS contributed to the acquisition of data. NM, RNS, and MAH contributed to the analysis and interpretation of data. NM, RNS, SE, AJ, and LS contributed to the drafting of the manuscript. NM, RNS, SE, AJ, LS, LP, and JC contributed to the critical revision of manuscript for important intellectual content. NM and RNS contributed to the statistical analysis. LS obtained the funding. SE and LS did the study supervision. All authors read and approved the final manuscript.

\section{Ethics approval and consent to participate}

The NYS Psychiatric Institute Institutional Review Board approved this study.

\section{Consent for publication}

N/A

\section{Competing interests}

Ravi N. Shah is a Clinical Advisor with $<1 \%$ equity in Two Chairs Clinic, which was not involved in the conduct of this study. The other authors declare that they have no competing interests.

\section{Publisher's Note}

Springer Nature remains neutral with regard to jurisdictional claims in published maps and institutional affiliations.

\section{Author details}

'Center for Behavioral and Cardiovascular Health, Department of Medicine, Columbia University Medical Center, 622 W. 168th Street, PH9- Room 321, New York, NY 10032, USA. ${ }^{2}$ Department of Psychiatry, Columbia University College of Physicians and Surgeons, New York, NY, USA. ${ }^{3}$ Columbia University Mailman School of Public Health, New York, NY, USA . ${ }^{4}$ Department of Epidemiology and Biostatistics and Medicine, Center for Vulnerable Populations, University of California, San Francisco, San Francisco, CA, USA. ${ }^{5}$ Icahn School of Medicine at Mount Sinai, New York, NY, USA. ${ }^{6}$ Columbia University Mailman School of Public Health, New York, NY, USA.

\section{Received: 11 March 2018 Accepted: 11 September 2018}

\section{Published online: 12 October 2018}

\section{References}

1. Unutzer J HH, Schoenbau M., Druss B. The collaborative care model: An approach for integrated physicial and mental health care in meidcad health homes. Health Home Information Resource Center Brief May 2013. https:// www.chcs.org/media/HH_IRC_Collaborative_Care_Model_052113_2.pdf. Accessed 23 Sept 2018.

2. Siu AL, the USPSTF. Screening for depression in adults: US preventive services task force recommendation statement. JAMA. 2016;315(4):380-7.

3. Thota AB, Sipe TA, Byard GJ, Zometa CS, Hahn RA, McKnight-Eily LR, et al. Collaborative care to improve the management of depressive disorders: a community guide systematic review and meta-analysis. Am J Prev Med. 2012;42(5):525-38.

4. Arean PA, Ayalon L, Hunkeler E, Lin EH, Tang L, Harpole L, et al. Improving depression care for older, minority patients in primary care. Med Care. 2005; 43(4):381-90.
5. Arean PA, Gum AM, Tang L, Unutzer J. Service use and outcomes among elderly persons with low incomes being treated for depression. Psychiatr Serv. 2007;58(8):1057-64.

6. Rost K, Nutting P, Smith J, Werner J, Duan N. Improving depression outcomes in community primary care practice: a randomized trial of the quEST intervention. Quality enhancement by strategic teaming. J Gen Intern Med. 2001;16(3):143-9.

7. Rost K, Smith JL, Dickinson M. The effect of improving primary care depression management on employee absenteeism and productivity. A randomized trial. Med Care. 2004;42(12):1202-10.

8. Jarjoura D, Polen A, Baum E, Kropp D, Hetrick S, Rutecki G. Effectiveness of screening and treatment for depression in ambulatory indigent patients. J Gen Intern Med. 2004;19(1):78-84.

9. Unützer J, Katon W, Callahan CM, et al. Collaborative care management of late-life depression in the primary care setting: a randomized controlled trial. JAMA. 2002;288(22):2836-45.

10. Gallo JJ, Morales KH, Bogner HR, Raue PJ, Zee J, Bruce ML, et al. Long term effect of depression care management on mortality in older adults: followup of cluster randomized clinical trial in primary care. BMJ. 2013;346:f2570.

11. Unutzer J, Katon WJ, Fan MY, Schoenbaum MC, Lin EH, Della Penna RD, et al. Long-term cost effects of collaborative care for late-life depression. Am J Manag Care. 2008;14(2):95-100.

12. Fortney J, Enderle M, McDougall S, Clothier J, Otero J, Altman L, et al. Implementation outcomes of evidence-based quality improvement for depression in VA community based outpatient clinics. Implement Sci. 2012;7:30

13. Tai-Seale M, Kunik ME, Shepherd A, Kirchner J, Gottumukkala A. A case study of early experience with implementation of collaborative care in the veterans health administration. Popul Health Manag. 2010;13(6):331-7.

14. Njeru JW, DeJesus RS, St Sauver J, Rutten L, Jacobson DJ, Wilson P, et al. Utilization of a mental health collaborative care model among patients who require interpreter services. Int J Ment Heal Syst. 2016;10:15.

15. Williams MD, Jaeckels N, Rummans TA, Somers K, Nesse RE, Gorman RS. Creating value in depression management. Qual Prim Care. 2010;18(5):327-33.

16. Institute for Clinical Systems Improvement (ICSI). The DIAMOND Program: Treatment for Patients with Depression in Primary Care Bloomingon, MN ICSI; 2014. Available from: https://www.icsi.org/_asset/rs2qfi/ DIAMONDWP0614.pdf.

17. Solberg LI, Crain AL, Jaeckels N, Ohnsorg KA, Margolis KL, Beck A, et al. The DIAMOND initiative: implementing collaborative care for depression in 75 primary care clinics. Implement Sci. 2013;8:135.

18. Dickinson WP. Strategies to support the integration of behavioral health and primary care: what have we learned thus far? J Am Board Fam Med. 2015;28(Supplement 1):S102-S6.

19. Gold SB, Green LA, Peek C. From our practices to yours: key messages for the journey to integrated behavioral health. J Am Board Fam Med. 2017; 30(1):25-34.

20. Miller BF. When frontline practice innovations are ahead of the health policy community: the example of behavioral health and primary care integration. J Am Board Fam Med. 2015;28(Supplement 1):S98-S101.

21. Green $L A$, Cifuentes M. Advancing care together by integrating primary care and behavioral health. J Am Board Fam Med. 2015;28(Supplement 1):S1-6.

22. Carvajal DN, Blank AE, Lechuga C, Schechter C, McKee MD. Do primary care patient experiences vary by teaching versus nonteaching facility? J Am Board Fam Med. 2014;27:239-48.

23. Chang ETMJ, Chaney E, Lanto A, Simon B, Yano EM, Rubenstein LV. Predictors of primary care management of depression in the veterans affairs healthcare system. J Gen Intern Med. 2014;29(7):1017-25.

24. Papanikolaou PNCG, loannidis JP. Patient outcomes with teaching versus nonteaching healthcare: a systematic review. PLoS Med. 2006;3(9):e341.

25. Sederer LI, Derman M, Carruthers J, Wall M. The New York State collaborative care initiative: 2012-2014. Psychiatr Q. 2016;87(1):1-23.

26. LR FPN. Are we there yet? Data saturation in qualitative research. Qual Rep. 2015;20(9):1408-16.

27. Whitebird RR, Solberg LI, Jaeckels NA, Pietruszewski PB, Hadzic S, Unutzer J, et al. Effective implementation of collaborative care for depression: what is needed? Am J Manag Care. 2014;20(9):699-707.

28. Crabtree B, Miller W. A template approach to text analysis: Developing and using codebooks. In: Crabtree B, Miller W, editors. Doing qualitative research. Newbury Park: Sage; 1999. p. 163-77.

29. Braun V, Clark, V Using thematic analysis. Qualitative Research in Psychology. 2008;3(2):77-101. 
30. Fereday J, Muir-Cochrane E. Demonstrating Rigor Using Thematic Analysis: A Hybrid Approach of Inductive and Deductive Coding and Theme Development. Int J Qual Methods. 2006;5(1):Article 1.

31. Teddlie C, Tashakkori A. The analysis of mixed methods data. In: Tashakkori A, Teddlie C, editors. Foundations of mixed methods research : integrating quantitative and qualitative techniques in the social and behavioral sciences. London: Sage; 2009. p. 249-84.

32. Krippendorff K. Content analysis : an introduction to its methodology. London: Sage; 2013.

33. Sederer LI. What does it take for primary care practices to truly deliver behavioral health care? JAMA Psychiatry. 2014;71(5):485-6.

34. Palinkas LA, Ell K, Hansen M, Cabassa L, Wells A. Sustainability of collaborative care interventions in primary care settings. J Soc Work. 2011;11:99.

35. Ivers $\mathrm{N}$, Jamtvedt $\mathrm{G}$, Flottorp S, Young JM, Odgaard-Jensen J, French SD, O'Brien MA, Johansen M, Grimshaw J, Oxman AD. Audit and feedback: effects on professional practice and healthcare outcomes. Cochrane Database Syst Rev. 2012;6:CD000259. https://doi.org/10.1002/14651858. CD000259.pub3.

36. Farrand P, Confue P, Byng R, Shaw S. Guided self-help supported by paraprofessional mental health workers: an uncontrolled before--after cohort study. Health Soc Care Community. 2009;17(1):9-17.

37. Chapman E, Chung H, Pincus HA. Using a continuum-based framework for behavioral health integration into primary care in New York State. Psychiatr Serv. 2017;68(8):756-8.

Ready to submit your research? Choose BMC and benefit from:

- fast, convenient online submission

- thorough peer review by experienced researchers in your field

- rapid publication on acceptance

- support for research data, including large and complex data types

- gold Open Access which fosters wider collaboration and increased citations

- maximum visibility for your research: over $100 \mathrm{M}$ website views per year

At BMC, research is always in progress.

Learn more biomedcentral.com/submissions 